\title{
A Novel Method of Combining Solid Phase Extraction with Solidified Floating Organic Drop Microextraction for Speciation of Inorganic Arsenic in Wastewater Samples by Electrothermal Vaporization ICP-MS
}

\author{
Shizhong Chen ${ }^{a *}$, Juntao Yan ${ }^{\mathrm{b}}$, Jianfen $\mathrm{Li}^{\mathrm{b}}$, Yan Zhang ${ }^{\mathrm{b}}$, and Dengbo Lu ${ }^{\mathrm{a}}$ \\ a College of Food Science and Engineering, Wuhan Polytechnic University, Wuhan 430023, P.R. China \\ b College of Chemical and Environmental Engineering, Wuhan Polytechnic University, \\ Wuhan 430023, P.R. China
}

\section{INTRODUCTION}

It is well known that arsenic (As) is one of the most toxic elements and has serious effects on human health. What is more, the toxicity, bioavailability, and reactivity of As are strongly dependent on its chemical forms (1-3). In environmental samples, arsenic exists predominantly in two chemical forms: As(III) and As(V). The inorganic species of As are more toxic than its organic ones (4). The toxicity of As(III) is 10-20 times higher than that of $A s(V)$ (5). Thus, it is highly desirable to develop an efficient method for the determination of the individual arsenic species in order to estimate their environmental impact and health risks.

Owing to its very low concentration and serious matrix interference, speciation analysis for an element is still a very challenging task in a complex sample matrix. In general, wastewater samples have complex matrices such as inorganic and organic compounds. Therefore, an effective method is required for the preconcentration and separation of elemental species from the matrix before their determination. Of the many separation and preconcentration techniques, solid phase extraction (SPE) has the potential ability for sample cleanup in addition to its major advantages of simple operation, fast kinetics, low cost, rapid phase separation, and easy automation (6). It is worth noting that the

*Corresponding autbor.

:E-mai; chenshizbong62@163.com

Tel: +862783956442

\section{ABSTRACT}

In this work, a novel method of combining solid phase extraction (SPE) with solidified floating organic drop microextraction (SFODME) was developed for the speciation of inorganic arsenic in wastewater samples by electrothermal vaporization inductively coupled plasma mass spectrometry. In the SPE step, titanium dioxide nanotubes were used for preconcentration of the analytes and removal of the inorganic and organic matrix from the wastewater samples. The elution solution from the SPE was employed for further preconcentration and separation of the analytes with SFODME. The main factors affecting the separation and determination of the analytes were also examined in detail. Under optimal conditions, the detection limits of this method were 0.073 and $0.089 \mathrm{pg} \mathrm{mL}^{-1}$ with relative standard deviations of $5.9 \%$ and $4.7 \%$ for $\mathrm{As}(\mathrm{III})$ and $\mathrm{As}(\mathrm{V})(\mathrm{n}=9$, $\left.\mathrm{c}=1.0 \mathrm{ng} \mathrm{mL}^{-1}\right)$, respectively. This method was successfully applied for the speciation of inorganic arsenic in industrial wastewater, urban sewage, and certified reference material of water sample without any prereduction and pre-oxidation operation.

adsorbent plays a fundamentally crucial role in SPE. In recent years, nanostructure material has drawn growing attention in analytical sciences (7-12). As a new and excellent material, titanium dioxide nanotubes (TDNTs) have shown a great potential for an element and its speciation owing to large specific surface area, high chemical stability, corrosion resistance, nontoxicity, and low cost (13-16). SPE could provide excellent sample cleanup ability, but it consumes large sample volume if enrichment factor (EF) is anticipated, resulting in a long analysis time.

In recent years, a series of miniaturized sample pretreatment procedures have emerged for the preconcentration and separation of trace/ ultra-trace analytes and liquid phase microextraction (LPME) has attracted considerable interest (17). Unfortunately, LPME suffers seriously from a complex or "dirty" sample matrix. Therefore, a lot of work performed for element speciation by LPME mainly focuses on the analysis of natural water samples with a simple matrix. Since SPE has excellent sample cleanup ability and LPME has high EF, the coupling of SPE with LPME will endow the dual extraction technique of both excellent anti-interference ability and high EF. Until now, the dual extraction techniques of dispersive liquid-liquid microextraction combined with SPE have been proposed for the determination of trace/ultra-trace analytes in real samples (18-21). As a new LPME technique, solidified floating organic drop microextraction (SFODME) has been used widely for the analysis of real samples because of simplicity, low cost, consumption of small organic solvent, and high EF (22-27). To the best of our knowledge, however, SFODME combined with SPE for 
inorganic As speciation in wastewater samples with a complex matrix has so far received little attention.

Inductively coupled plasma mass spectrometry (ICP-MS) has proven to be one of the most favorable analysis tools for elements and its speciation owing to its high sensitivity, wide linear dynamic range, and rapid multielement detection capability. However, use of an organic solvent in chemical pretreatment and the high matrix content in the samples may lead to destabilization or extinction of the ICP discharge owing to the relative high solvent vapor pressure and the extra matrix loading. Electrothermal vaporization (ETV), as a sample introduction device for ICP-MS, has the advantages of high introducing efficiency, small sample requirement, low absolute detection limit, and partial or complete removal of the organic/inorganic solvent/ matrix. In addition, utilization of a chemical modifier in ETV, especially organic chelating reagents, could greatly improve the analytical performance of the method (2832).

The aim of this work was to develop a novel method of combining SPE with SFODME for the speciation of inorganic As by ETV-ICP-MS in wastewater samples with complex matrices. In the first SPE step, a microcolumn packed with TDNTs as the adsorbent was used for concentration of the analytes and removal of the matrix from the wastewater samples. And then, the elution solution from SPE was buffered and employed for further preconcentration and separation of the analytes with SFODME using APDC as a chelating reagent and 1-undecanol as an extraction solvent. Finally, the extracts from SFODME were used for ETV-ICP-MS determination with APDC as a chemical modifier. This method was applied for the determination of the species of inorganic As in industrial wastewater and urban sewage samples with satisfactory results.

\section{EXPERIMENTAL}

\section{Instrumentation}

An X-7 ICP-MS system (Thermo Elemental Corporation, USA), equipped with a modified commercially available WF-4C graphite furnace (Beijing Second Optics, P.R. China) as an electrothermal vaporizer, was used for the determination of the analytes. The operating parameters of ICP-MS were optimized with a concentric glass nebulizer prior to connection with the ETV device. A pyrolytic graphite tube was used throughout this work. The working conditions of ETV-ICP-MS are summarized in Table I. The $\mathrm{pH}$ value of the solution was controlled with a $\mathrm{pH}$ meter (Thermo Orion Corporation, USA) supplied with a combined electrode.

\section{Atomic Apectroscopy Vol. 38(1), Jan./Feb. 2017}

\section{Standard Solutions and Reagents}

The stock standard solutions (1.0 $\mathrm{mg} \mathrm{mL}^{-1}$ ) of As(III) and As(V) were obtained by dissolving appropriate amounts of $\mathrm{Na}_{3} \mathrm{AsO}_{3}$ and $\mathrm{Na}_{3} \mathrm{AsO}_{4} \cdot 12 \mathrm{H}_{2} \mathrm{O}$ (Tianjin Reagent Factory, Tianjin, P.R. China) in high purity deionized water, respectively. All reagents in this study were of high purity or at least of analytical grade, and deionized water obtained from a Milli-Q ${ }^{\circledR}$ A10 system (Millipore Corporation, USA) was used throughout this work. The working solutions were prepared daily by appropriate dilution of the stock solutions. The APDC solution was prepared by dissolving the proper amount of APDC (Shanghai Reagent Factory, P.R. China) in 1-undecanol (Shanghai Reagent Factory, P.R. China). The TDNTs were synthesized and characterized in our laboratory. All glass and polypropylene wares were kept in $2.0 \mathrm{~mol} \mathrm{~L}^{-1} \mathrm{HNO}_{3}$ solution

TABLE I

Operating Parameters for ETV-ICP-MS

\begin{tabular}{ll}
\hline ICP-MS Plasma & \\
\hline Plasma Power & $1300 \mathrm{~W}$ \\
Plasma Argon Flow Rate & $14.5 \mathrm{~L} \mathrm{~min}^{-1}$ \\
Auxiliary Argon Flow Rate & $0.84 \mathrm{~L} \mathrm{~min}^{-1}$ \\
Nebulizer Argon Flow Rate & $0.91 \mathrm{~L} \mathrm{~min}^{-1}$ \\
Sampler Orifice (nickel) & $1.1 \mathrm{~mm}$ \\
Skimmer Orifice (nickel) & $0.7 \mathrm{~mm}$ \\
Acquisition Mode & Peak jumping \\
Number of Sweeps & 100 \\
Dwell Time & $10 \mathrm{~ms}$ \\
Acquisition Time & $40 \mathrm{~s}$ \\
Number of Measurements per Peak & 3 \\
Isotopes & $75 \mathrm{As}$ \\
\hline ETV & \\
\hline Sample Volume & $10 \mu \mathrm{L}$ \\
Carrier Gas Flow Rate & $0.43 \mathrm{~L} \mathrm{~min}-1$ \\
Drying Step & $100{ }^{\circ} \mathrm{C}$, ramp $10 \mathrm{~s}$, hold $10 \mathrm{~s}$ \\
Ashing Step & $200{ }^{\circ} \mathrm{C}$, ramp $10 \mathrm{~s}$, hold $30 \mathrm{~s}$ \\
Vaporization Step & $2000{ }^{\circ} \mathrm{C}$, hold $4 \mathrm{~s}$ \\
Clear-out Temperature & $2600{ }^{\circ} \mathrm{C}$ \\
\hline
\end{tabular}


for at least one night, then rinsed with $0.1 \mathrm{~mol} \mathrm{~L}^{-1} \mathrm{HNO}_{3}$ solution and subsequently with deionized water.

\section{Sample Pretreatment}

Wastewater samples (Wuhan, P.R. China) were collected in 50-mL polyethylene containers. The wastewater samples were filtered through a $0.45-\mu \mathrm{m}$ membrane filter and then stored in polyethylene bottles at $4{ }^{\circ} \mathrm{C}$ for future use. The storage period was kept as short as possible. Blanks were prepared exactly as the samples except that no analytes were added.

\section{Solid Phase Extraction}

A PTFE microcolumn $(20 \mathrm{~mm} \times$ $3.0 \mathrm{~mm}$ i.d.) plugged with a small portion of glass wool at both ends was filled with $50 \mathrm{mg}$ of TDNTs. Before use, $2.0 \mathrm{~mL}$ of $1.0 \mathrm{~mol} \mathrm{~L}^{-1}$ $\mathrm{HNO}_{3}$ solution and $10 \mathrm{~mL}$ of deionized water were passed through the column to clean and condition it, respectively. Then, a 10-mL aliquot of the sample was passed through the column by using a peristaltic pump. The retained analytes were eluted with $2.0 \mathrm{~mL}$ of $0.20 \mathrm{~mol} \mathrm{~L}^{-1}$ $\mathrm{NaOH}$ solution. Finally, $2.0 \mathrm{~mL}$ of desorption solution was transferred into a $10-\mathrm{mL}$ vial for SFODME.

\section{Solidified Floating Organic Drop Microextraction}

A 2.0-mL aliquot of desorption solution was taken into a $10-\mathrm{mL}$ vial, adjusted to the desired $\mathrm{pH}$ values using diluted $\mathrm{HNO}_{3}$ and $\mathrm{NaOH}$ solution, and finally calibrated to $5.0 \mathrm{~mL}$. A stir bar and $20 \mu \mathrm{L}$ of APDC in 1-dodecanol were added. The magnetic stirrer was turned on, and the solution was stirred for a fixed time. In this step, analytes react with APDC to form hydrophobic complexes and were extracted into 1-undecanol. After the extraction process was finished, the sample vial was transferred into an ice bath until the organic solvent solidified. The solidified solvent was then transferred into a conical vial where it melted immediately at room temperature. The extract was diluted to $100 \mu \mathrm{L}$ with tetrahydrofuran (THF). Finally, $10 \mu \mathrm{L}$ of the extract was injected into the graphite tube for ETV-ICP-MS analysis.

\section{ETV-ICP-MS Procedure}

After the ETV unit had been connected to the ICP-MS, $10 \mu \mathrm{L}$ of the analytes in the organic solvent was injected into the graphite furnace. During the drying and charring process, the dosing hole of the graphite furnace was kept open to remove the water and the organic vapor. Then it was sealed with a graphite probe within 5-10 seconds prior to the vaporization step, the vaporized analytes were swept into the plasma excitation source by a carrier gas, and the peak-hop transient mode for data acquisition was used for the detection of the analytes.

\section{RESULTS AND DISCUSSION}

\section{Selection of SPE Conditions}

The column variables for SPE were optimized by conventional pneumatic nebulization (PN)-ICPMS in detail, including $\mathrm{pH}$, eluent concentration/volume, and sample flow rate/volume.

The $\mathrm{pH}$ value plays an essential role with respect to the adsorption of the analytes on TDNTs during the SPE procedure. Therefore, the effect of sample $\mathrm{pH}$ on the adsorption of the analytes on TDNTs was investigated in the $\mathrm{pH}$ range of 3.011. The results demonstrate that in the $\mathrm{pH}$ range of 3.0-6.0, As(III) and As(V) were quantitatively retained on the TDNTs; As(III) was only quantitatively adsorbed by the TDNTs within the $\mathrm{pH}$ range of 6.0-10, while As(V) was not quantitatively retained on the TDNTs at the same $\mathrm{pH}$ range. Based on the facts mentioned above, $\mathrm{pH} 4.0$ was selected for the preconcentration of the sum of As(III) and As(V) in this work.
The choice of a suitable eluent is very important for the successful coupling of a microcolumn preconcentration system to ICP-MS. In this work, it can be found that the adsorption percentages of the analytes on the TDNTs decreased significantly at $\mathrm{pH}>10$. Thus, the different concentrations of $\mathrm{NaOH}$ solution were studied for desorption of the retained analytes. In the experiment, it was found that the retained species could be eluted quantitatively with $2.0 \mathrm{~mL}$ of 0.20 mol L ${ }^{-1} \mathrm{NaOH}$ solution. Thus, 2.0 $\mathrm{mL}$ of $0.20 \mathrm{~mol} \mathrm{~L}^{-1} \mathrm{NaOH}$ solution was used for the quantitative elution of the analytes.

The effect of sample flow rate on adsorption percentage of the analytes was investigated in the range of 0.2 to $3.0 \mathrm{~mL} \mathrm{~min}{ }^{-1}$. The experimental results indicated that there was a decrease in the recoveries of the analytes at a flow rate

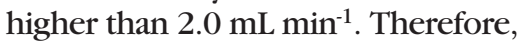
all subsequent experiments were performed at a flow rate of $1.5 \mathrm{~mL}$ $\mathrm{min}^{-1}$. The effect of sample volume on the adsorption of the analytes was studied in the range of 10-120 $\mathrm{mL}$ containing $2.0 \mathrm{ng}$ of the analytes. The experimental results showed that quantitative recoveries (>90\%) were obtained for sample volumes up to $100 \mathrm{~mL}$. Considering the analysis time, a 10-mL sample volume was used for the analysis of real samples.

\section{Optimization of SFOME Parameters}

In this work, APDC and 1-undecanol were selected as a chelating reagent and an extractant in SFOME, respectively. The main factors affecting the complex formation and extraction of the analytes were investigated with model solutions (without the SPE step).

Due to its influence on the existing form of the analytes and APDC, sample acidity plays a key role in the complex formation and subse- 
quent extraction. Thus, the effect of sample acidity on the signal intensities of the analytes was investigated in detail. For the sake of simplicity and clarity, the $\mathrm{X}$-axis was expressed in $\mathrm{HCl}$ concentration $(\mathrm{pH}<0)$ and $\mathrm{pH}$ values $(\mathrm{pH}>0)$, respectively. As shown in Figure 1, the maximum signal intensity of As(III) was obtained in the acidity range of $3.0 \mathrm{~mol} \mathrm{~L}^{-1} \mathrm{HCl}-\mathrm{pH} 6.0$, whereas the maximal signal of As(V) was recorded with an $\mathrm{HCl}$ concentration varying from 1.0 - 3.0 mol L$~^{-1}$. It is worth noting that with a $\mathrm{pH}>4.0$, no signal was detected for As(V). Based on the results mentioned above, $2.0 \mathrm{~mol} \mathrm{~L}^{-1} \mathrm{HCl}$ solution was chosen for the preconcentration of the sum of As(III) and As(V), and pH 5.0 was used for the separation of As(III) and As(V) by SFODME.

The effect of APDC concentration on the signal intensity of the analytes was studied in the concentration range of $0.1 \times 10^{-2}-4.0 \times 10^{-2}$ mol L ${ }^{-1}$. The results indicated that the signal intensities of the analytes increased with an increase in APDC concentration from $0.1 \times 10^{-2}$ to $1.0 \times 10^{-2} \mathrm{~mol} \mathrm{~L}^{-1}$, and then kept nearly constant when the concentration of APDC exceeded $2.0 \times 10^{-2}$ mol L-1 . Thus, a relatively high concentration of $3.0 \times 10^{-2}$ mol L-1 APDC was used for subsequent work.

The effect of extraction time on the signal intensity of the analytes was investigated by varying the extraction time from 5 to $30 \mathrm{~min}$ utes. The experimental results showed that the signal intensity of the analytes increased with an increase in extraction time, and then reached a plateau after 20 minutes. Thus, an extraction time of 20 minutes was used in this work. In addition, the temperature for SFODME has an important effect on both phase equilibrium and mass transfer. The results showed that the signal intensity of the analytes increased by raising the sample temperature up to $40^{\circ} \mathrm{C}$. However, the signal intensity of the analytes decreased with an increase in temperature to higher than $50^{\circ} \mathrm{C}$. Thus, the sample temperature was adjusted to $45^{\circ} \mathrm{C}$ in this work.

In order to accelerate mass-transfer of the analytes from the aqueous to the organic phase, the sample solution of $10 \mathrm{~mL}$ was continuously agitated at different stirring rates from 100 to $1200 \mathrm{rpm}$. The experimental results showed that the signal intensities of the analytes increased rapidly with an increase of the stirring rate up to $900 \mathrm{rpm}$. Hence, a stirring rate of

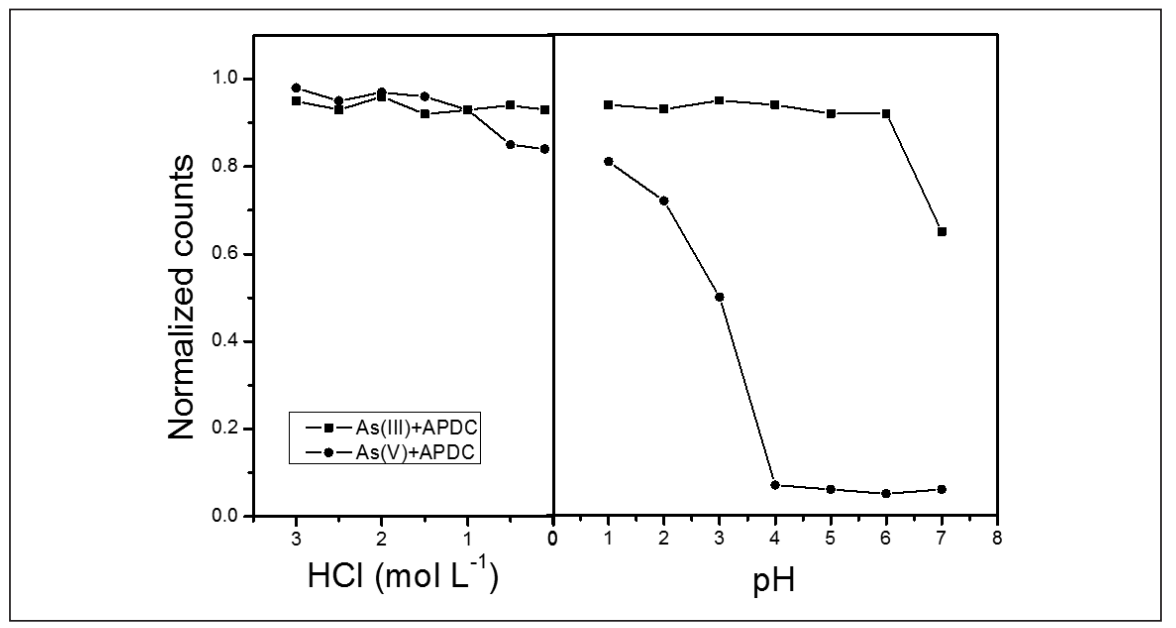

Fig. 1. Effect of sample acidity on signal intensity of analytes in SFODME. As(III) and As(V): $1.0 \mathrm{ng} \mathrm{mL}^{-1}$; Vaporization temperature: $2000^{\circ} \mathrm{C}$.

\section{Atomic Apectroscopy Vol. 38(1), Jan./Feb. 2017}

$900 \mathrm{rpm}$ was employed in this work.

The effect of sample volume on the extraction efficiency was investigated using different sample volumes $(1.0-30 \mathrm{~mL})$. The results indicated that the extraction was quantitative (recovery $>90 \%$ ) with an aqueous phase volume ranging from 10-20 mL. However, a decrease was observed with a further increase in sample volume. Based on the organic phase volume $(20 \mu \mathrm{L})$ and the maximum sample volume $(10 \mathrm{~mL})$, an enrichment factor of 500 was obtained for the analytes.

\section{Interference of Coexisting Ions}

In order to evaluate the application potential of this method, the effect of various cations and anions commonly existing in environmental water samples on the extraction and determination of the analytes was examined. The tolerance limit of coexisting ions is defined as the largest amount making a variation of less than $10 \%$ in the recovery of analytes. The results obtained are summarized in Table II. As can be seen, this method has high tolerance limits to alkaline, alkaline earth metal ions, and anions since they have negligible interaction with APDC. The tolerance limits of $\mathrm{Al}^{3+}, \mathrm{Zn}^{2+}$, and $\mathrm{Fe}^{3+}$ were not as high as other interference ions, mainly because they can react with APDC and then enter the competitive reaction with the analytes. For this reason, the excessive chelating

TABLE II

Effect of Interfering Ions

\begin{tabular}{lc}
\hline $\begin{array}{l}\text { Diverse } \\
\text { Ions }\end{array}$ & $\begin{array}{c}\text { Concentration } \\
\text { Ratio }\end{array}$ \\
\hline $\mathrm{Na}^{+}, \mathrm{K}^{+}$ & 30,000 \\
$\mathrm{Ca}^{2+}, \mathrm{Mg}^{2+}$ & 20,000 \\
$\mathrm{Fe}^{3+}, \mathrm{Zn}^{2+}, \mathrm{Al}^{3+}$ & 500 \\
$\mathrm{SO}_{4}{ }^{2-}, \mathrm{SiO}_{3}{ }^{2-}, \mathrm{PO}_{4}{ }^{3-}$ & 20,000 \\
$\mathrm{Cl}^{-}, \mathrm{NO}_{3}^{-}$ & 30,000 \\
\hline
\end{tabular}

${ }^{\text {a }}$ Foreign ion / analyte. 
reagent was necessary for this experiment.

\section{Optimization of ETV Variables}

The experimental results showed that a drying temperature of $100^{\circ} \mathrm{C}$ and a drying time of 10 seconds were used for removal of the water vapor during the drying step; a pyrolysis temperature of 200 ${ }^{\circ} \mathrm{C}$ and a pyrolysis time of 20 seconds were used for in situ removal of the extraction solvent from the furnace without signal loss of the analytes. In addition, under the selected drying and pyrolysis conditions, the effect of vaporization temperature on the signal intensity of the analytes was studied with a vaporization time of 4 seconds. The experimental results showed that with APDC as the chemical modifier, maximum signals were obtained at $1800{ }^{\circ} \mathrm{C}$ for the analytes, and then kept constant with a further increase of vaporization temperature to $2200{ }^{\circ} \mathrm{C}$. Therefore, a vaporization temperature of $2000{ }^{\circ} \mathrm{C}$ and a vaporization time of 4 seconds were used in this work.

\section{Analytical Performance}

Some important analytical parameters of this method, including precision, linear range of the calibration curve and detection limits, were carried out under the optimum experimental conditions. The detection limits of As(III) and As(V), based on three times the standard deviation of the blank solution, were $0.073 \mathrm{pg} \mathrm{mL}^{-1}$ and $0.089 \mathrm{pg} \mathrm{mL}^{-1}$, respectively. The relative standard deviations were 5.9\% and $4.7 \%$ for As(III) and As(V) $\left(\mathrm{n}=9, \mathrm{c}=1.0 \mathrm{ng} \mathrm{mL}^{-1}\right)$, respectively. The linear dynamic range of the calibration curve covered three orders of magnitude with a correlation coefficient better than 0.9946 .

\section{Sample Analysis}

This method was applied for the analysis of inorganic As species in wastewater samples. The results listed in Table III are in good agree-

TABLE III

Analytical Results and Recoveries of Analytes in Wastewater Samples

\begin{tabular}{lccccc}
\hline Sample & Species & $\begin{array}{c}\text { Content } \\
\left(\mathrm{ng} \mathrm{mL}^{-1}\right)\end{array}$ & $\begin{array}{c}\text { Added } \\
\left(\mathrm{ng} \mathrm{mL}^{-1}\right)\end{array}$ & $\begin{array}{c}\text { Found }^{\mathrm{a}} \\
\left(\mathrm{ng} \mathrm{mL}^{-1}\right)\end{array}$ & $\begin{array}{c}\text { Recovery } \\
(\%)\end{array}$ \\
\hline Industrial Wastewater & As(III) & $32.4 \pm 2.41$ & 10 & $42.1 \pm 3.25$ & 97.0 \\
& As(V) & $17.9 \pm 1.34$ & 10 & $28.1 \pm 1.65$ & 102 \\
& & & & & \\
Urban Sewage & As(III) & $5.48 \pm 0.37$ & 5.0 & $10.3 \pm 0.61$ & 96.4 \\
& As(V) & $3.12 \pm 0.19$ & 5.0 & $8.01 \pm 0.47$ & 97.8 \\
\hline
\end{tabular}

${ }^{a}$ Mean value \pm standard deviation, $n=5$

TABLE IV

Analytical Results of Analytes in Certified Reference Material of Water Sample

\begin{tabular}{llcc}
\hline Sample & Element & Found $^{\mathrm{a}}\left(\mu \mathrm{g} \mathrm{mL}^{-1}\right)$ & Certified $\left(\mu \mathrm{gL}^{-1}\right)$ \\
\hline Water Sample & & & \\
(GSBZ50004-88) & Total As & $0.0506 \pm 0.0028$ & $0.0479 \pm 0.0025$ \\
& As(III) & $0.0045 \pm 0.0002$ & - \\
& As(V) & $0.0436 \pm 0.0021$ & -
\end{tabular}

${ }^{a}$ Mean value \pm standard deviation, $n=5$.

ment between the added and measured analyte amounts. The recoveries of the analytes were in the range of $96.4-102 \%$. The reliability was checked by the analysis of a certified reference material of water sample (GSBZ50004-88), obtained from the Institute for Reference Materials of SEPA (Beijing, P.R. China). The results were in good agreement with the certified value (Table IV).

\section{CONCLUSION}

In summary, a novel method of combining SPE with SFODME was developed for inorganic As species in the wastewater samples prior to ETV-ICP-MS determination. In the first extraction step of SPE, the analytes were adsorbed on the DTNTs, and then desorbed by $0.2 \mathrm{ml} \mathrm{L}^{-1}$ $\mathrm{NaOH}$ solution, realizing the preliminary preconcentration and separation of the analytes from the complex sample matrix. And the analytes were further preconcentrated and separated by SFODME with APDC as the chelating reagent. Finally, the extracts obtained from SFODME were determined by ETV-ICP-MS with APDC as a chemical modifier. In addition, this method also offers high EF, low detection limit, simple operation, good accuracy, and without prereduction and pre-oxidation operation. This combination of a different preconcentration/separation method not only has excellent sample cleanup ability, but also improves the analytical performance. It is likely to become a novel strategy for the elemental speciation in a complex matrix sample.

\section{ACKNOWLEDGMENT}

The authors are grateful for the financial support of Special Fund for Agroscientific Research in the Public Interest (Project No. 201503135-22), P.R. China.

Received June 9, 2016. 


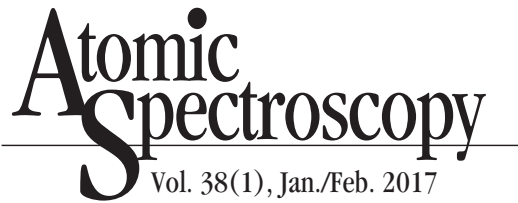

\section{REFERENCES}

1. G. Yang, J. Zheng, L. Chen, Q. Lin, Y. Zhao, Y. Wu, and F. Fu, Food Chem. 132(3), 1480 (2012).

2. B.S. Pinheiro, L.L.S. Gimenes, A.J. Moreira, C.D. Freschi, and G.P.G Freschi, At. Spectrosc. 37(2), 83 (2016).

3. J. Moreda-Pińeiro, E. AlonsoRodríguez, V. Romarís-Hortas, A. Moreda-Pińeiro, P. López-Mahía, S. Muniategui-Lorenzo, D. PradaRodríguez, and P. Bermejo-Barrera, Food Chem. 130, 552 (2012).

4. L.O. Leal, R. Forteza, and V. Cerdá, Talanta 69, 500 (2006).

5. J. Koh, Y. Kwon, and Y. Pak, Microchem. J. 80, 195 (2005).

6. V.A. Lemos, L.S.G. Teixeira, M. A. Bezerra, A.C.S. Costa, J.T. Castro, L.A.M. Cardoso, D.S. de Jesus, E.S Santos, P.X. Baliza, and L.N. Santos, Appl. Spectrosc. Rev. 43, 303 (2008).

7. S. Chen, M. Xiao, D. Lu, Z. Hu, and X. Zhan, At. Spectrosc. 28(3), 90 (2007).

8. S. Farid, D. Shayessteh, M.H.S. Ali, and N.A.A. Maryam, Food Chem. 145, 571 (2014).

9. G.A. Kandhro, S. Mustafa, and G.K. Tasneem, At. Spectrosc. 35, 270 (2014).

10. D. Chen, J. Deng, J. Liang, J. Xie, K.Huang, and C. Hu, Anal. Meth. 5(3), 722 (2013).

11. P. Krystyna, TrAC Trends Anal. Chem. 43, 100 (2013).

12. J. Zhang, X. Wang, Y. Dong, Z. Xu, and G. Li, At. Spectrosc. 37(1), 1 (2016).

13. M.T. García-Valverde, R. Lucena, S. Cárdenas, and M. Valcárcel, TrAC Trends Anal. Chem. 62, 37 (2014).

14. C. Shizhong, Z. Shengping, H. Yuanyuan, and L. Dengbo, Food Chem. 150, 254 (2014).

15. Z. Qingxiang, Z. Xinning, and $X$. Junping, Talanta 77, 1774 (2009).

16. Z. Yan, C. Shizhong, G. Xinle, and L. Dengbo, At. Spectrosc. 35, 235 (2014).

17. H. Dandan and H.R. Kyung, Microchim. Acta 176(1-2), 1 (2012).
18. G. Liang and K.L. Hian, J. Chromatogr. A 1300, 24 (2013).

19. F. Nazir, S. Soheila, A.Yaghoub, and R.M.H. Mohammad, J. Chromatogr. A 1169, 63 (2007).

20. D. Djavanshir, A.F. Mir, M.S. Saeed, and B. Tahmineh, J. Chromatogr. A 1248, 24 (2012).

21. X.Q. Guo, X.T. Tang, M. He, B.B. Chen, K. Nan, Q.Y. Zhang, and B. Hu, RSC Advances 4, 19960 (2014).

22. P. Li, X. Zhang, Y. Chen, H. Lian, and X. Hu, Anal. Meth. 6, 4205 (2014).

23. V. Pilar, C. Natalia, and A. Vasil, TrAC Trends Anal. Chem. 68, 48 (2015).

24. S. Hong, Z. Liping, Y. Binwu, and L. Qiao, At. Spectrosc. 35, 265 (2014).

25. W. Yongkui, W. Mei, W. Huili, W. Wenwei, W. Jia, and W. Xuedong, Food Chem. 173, 1213 (2015).

26. S. Chen, S. Zhu, and D. Lu, Food Chem. 169, 156 (2015).

27. S. Chen, Y. He, S. Zhu, and D. Lu, At. Spectrosc. 36(6), 247 (2016).

28. S. Chen, S. Zhu, and D. Lu, Microchem. J. 97, 196 (2011).

29. S. Chen and D. Lu, At. Spectrosc. 33(1), 9 (2011).

30. Y. Yi, S. Jiang, and A.C Sahayam, J. Anal. At. Spectrom. 27(3), 426 (2012)

31. Y. Yi, S. Wu, and S. Jiang, At. Spectrosc. 34, 39 (2013).

32. S. Huang and S. Jiang, Anal. Meth. 2, 1310 (2010). 